\title{
SURGICAL MANAGEMENT OF PROGRESSIVE PULMONARY VENOUS OBSTRUCTION AFTER REPAIR OF TOTAL ANOMALOUS PULMONARY VENOUS CONNECTION
}

François Lacour-Gayet, MDa

Joy Zoghbi, MD ${ }^{\mathrm{a}}$

Alain E. Serraf, MD

Emré Belli, MD ${ }^{\mathrm{a}}$

Dominique Piot, $\mathrm{MD}^{\mathrm{a}}$

Christian Rey, $\mathrm{MD}^{\mathrm{b}}$

François Marçon, MD $^{\mathrm{c}}$

Jacqueline Bruniaux, MD

Claude Planché, MD
Background: The occurrence of a progressive pulmonary venous obstruction after the repair of the total anomalous pulmonary venous connection is a severe complication. Objectives: The objectives of this study were to retrospectively review the patients with this condition and to report our experience with a new surgical technique with a sutureless in situ pericardium repair. Methods: Of 178 patients who underwent correction of total anomalous pulmonary venous connection, 16 patients $(9 \%)$ experienced the development of a progressive pulmonary venous obstruction in a median interval of 4 months (5 weeks-12 years). Three patients had isolated anastomotic stenosis, 4 patients had isolated pulmonary venous ostial stenosis, and 9 patients had both. Pulmonary venous obstruction was bilateral in 7 patients. The surgical procedures used at reoperation included 8 patch enlargements, 5 ostial endarterectomies, 1 intraoperative stenting, and 7 sutureless in situ pericardium repairs. Results: There were 4 deaths after reoperation (4 of 15 patients; $27 \%$ ). The only significant mortality risk factor was the bilateral location of the pulmonary venous obstruction $(P=.045)$. In patients with isolated anastomotic stenosis or with only 1 pulmonary venous ostial stenosis $(n=5)$, there was no death, except the patient presenting with a single ventricle. In patients with 2 or more pulmonary venous ostial stenoses $(n=10)$, there were 3 deaths; 5 of the 7 survivors were successfully treated with the in situ pericardial technique, with normalized pulmonary artery pressure at a mean follow-up of $\mathbf{2 6}$ months. Conclusion: Progressive pulmonary venous stenosis after repair of total anomalous pulmonary venous connection remains a severe complication when bilateral. The sutureless in situ pericardial repair offers a satisfactory solution, particularly on the right side. (J Thorac Cardiovasc Surg 1999;117: 679-87)
$\mathrm{D}$ espite improvements in the surgical repair of total anomalous pulmonary venous connection (TAPVC) ${ }^{1}$ the risk of progressive pulmonary venous obstruction (PVO) remains significant. It realizes a serious complication that is associated with a high risk of

From the Marie-Lannelongue Hospital, Paris-Sud University, ${ }^{\text {a Paris, }}$ France; Centre Hospitalier Régional de Lille, ${ }^{\mathrm{b}}$ Lille, France; and Centre Hospitalier Régional de Nancy, ${ }^{\mathrm{c}}$ Nancy, France.

Read at the Seventy-eighth Annual Meeting of The American Association for Thoracic Surgery, Boston, Mass, May 3-6, 1998.

Received for publication May 8, 1998; revisions requested June 12, 1998; revisions received Nov 30, 1998; accepted for publication Dec 11, 1998.

Address for reprints: François Lacour-Gayet, MD, Marie-Lannelongue Hospital, 133 Avenue de la Résistance, 92350, Le Plessis Robinson, France.

Copyright (C) 1999 by Mosby, Inc.

$0022-5223 / 99 \$ 8.00+0 \quad \mathbf{1 2 / 6 / 9 6 5 3 3}$ recurrence and a high mortality rate. The aim of this study was to retrospectively analyze cases of the patients who experienced progressive PVO after TAPVC repair and to report our experience with a new surgical technique with a sutureless procedure using in situ pericardium. ${ }^{2}$

\section{Patients and methods}

Patients. Of 178 patients who underwent correction of total anomalous pulmonary venous drainage (TAPVC) over the past 15 years, 16 patients $(9 \%$; $95 \%$ confidence limit, $0 \%$ $20 \%$ ) experienced the development of a progressive PVO. All included patients had satisfactory initial repair, documented by a postoperative Doppler echocardiogram that showed biphasic flow and maximal velocity less than $1.5 \mathrm{~m} / \mathrm{s}$ at the site of the pulmonary veins. Three patients who experienced the development of obvious PVO immediately after the operation were excluded from the study. There were 14 boys and 
Table I. Sixteen patients, according to number of PVOs

\begin{tabular}{|c|c|c|c|c|c|c|}
\hline $\begin{array}{l}\text { Patients in } \\
\text { chronologic } \\
\text { order }\end{array}$ & TAPVC type & $\begin{array}{l}\text { Anastomotic } \\
\text { obstruction }\end{array}$ & $P V O(n)$ & Side & Right & Left \\
\hline 6 & Supracardiac & 1 & 0 & 0 & & \\
\hline 8 & Supracardiac & 1 & 0 & 0 & & \\
\hline 9 & Supracardiac SV, heterotaxy & 1 & 0 & 0 & & \\
\hline 3 & Supracardiac & 1 & 1 & Unilateral & 1 & \\
\hline 7 & Infracardiac & 1 & 1 & Unilateral & & 1 \\
\hline 5 & Supracardiac & 1 & 2 & Unilateral & & 2 \\
\hline 12 & Mixed & 1 & 2 & Unilateral & 2 & \\
\hline 14 & Supracardiac & 1 & 2 & Unilateral & 2 & \\
\hline 16 & Infracardiac & 0 & 2 & Unilateral & 2 & \\
\hline 1 & Supracardiac & 0 & 2 & Bilateral & 1 & 1 \\
\hline 4 & Infracardiac & 0 & 3 & Bilateral & 2 & 1 \\
\hline 10 & Infracardiac & 1 & 3 & Bilateral & 2 & 1 \\
\hline 13 & Infracardiac & 1 & 3 & Bilateral & 2 & 1 \\
\hline 15 & Mixed & 1 & 3 & Bilateral & 2 & 1 \\
\hline 2 & Infracardiac & 0 & 4 & Bilateral & 2 & 2 \\
\hline 11 & Supracardiac & 1 & 4 & Bilateral & 2 & 2 \\
\hline
\end{tabular}

$P R V$, Systolic right ventricle pressure; $S V$, single ventricle; $B C P A$, bicavopulmonary anastomosis; $P H T$, pulmonary hypertension; $P V$, pulmonary vein; $M P A P$, mean pulmonary arterial pressure.

2 girls. Median age and weight at TAPVC repair were 11 days (1 day-3 months) and $3.3 \mathrm{~kg}$. Six patients were younger than 1 week of age. The anatomic types of TAPVC involved were supra cardiac in 8 patients, infradiaphragmatic in 5 patients, mixed in 2 patients, and intracardiac in 1 patient. The TAPVC was obstructed in 9 patients, including all infracardiac and mixed types and 2 supracardiac forms. One patient had a single functioning ventricle associated with visceral heterotaxy. The initial TAPVC repair followed a technique already described. ${ }^{1}$ The incision of the main pulmonary vein trunk was not extended to the pulmonary veins. The anastomosis between the confluence of the pulmonary vein and the left atrium was always performed with nonabsorbable suture material (7-0 or 8-0 polypropylene).

The free delay between the TAPVC repair and the occurrence of a PVO ranged from 5 weeks to 12 years, with a median delay of 4 months. The diagnosis was established by 2-D echocardiography with Doppler, which shows a continu- ous flow and a velocity of more than $2 \mathrm{~m} / \mathrm{s}$. It was always confirmed by catheterization and selective angiograms of the pulmonary branches. Pulmonary hypertension was constant, being isosystemic or suprasystemic in most of the patients.

Anatomic lesions. At reoperation, there was constantly an intimal hyperplasia with proliferation of an inflammatory thickened tissue. This intimal proliferation was limited at the site of the anastomosis between the common pulmonary vein and the left atrial wall in 3 patients with supracardiac TAPVC, creating an isolated anastomosis stenosis. In 4 other patients, the intimal hyperplasia involved the pulmonary vein ostia without anastomosis stenosis. Most frequently (in 9 patients) the intimal proliferation involved, at the same time, the anastomotic site and the individual pulmonary veins; the hyperplasia extended from the ostium of the pulmonary vein toward its extracardiac segment.

The number of pulmonary veins obstructed was different from 1 patient to another. As shown in Table I, the right-sided 


\begin{tabular}{|c|c|c|c|c|}
\hline 149 & Endarterectomy & & $\begin{array}{l}\text { Alive; echocardiography: } \\
\text { PRV, } 30 \mathrm{~mm} \mathrm{Hg}\end{array}$ & 51 \\
\hline 54 & Balloon dilation & & $\begin{array}{l}\text { Alive; echocardiography: } \\
\text { PRV, } 30 \mathrm{~mm} \mathrm{Hg}\end{array}$ & 41 \\
\hline 1.5 & Anastomotic patch enlargement; BCPA & & Operative death; PHT crisis & \\
\hline 5 & $\mathrm{PV}+$ anastomotic patch enlargement & & $\begin{array}{l}\text { Alive; echocardiography: } \\
\text { PRV, } 30 \mathrm{~mm} \mathrm{Hg}\end{array}$ & 144 \\
\hline 71 & $\begin{array}{l}\text { Anastomotic patch enlargement; } \\
\text { PV endarterectomy }\end{array}$ & & $\begin{array}{l}\text { Alive; echocardiography: } \\
\text { PRV, } 30 \mathrm{~mm} \mathrm{Hg}\end{array}$ & 41 \\
\hline 3 & $\mathrm{PV}+$ anastomotic patch enlargement & & $\begin{array}{l}\text { Alive; echocardiography: } \\
\text { PRV, } 40 \mathrm{~mm} \mathrm{Hg}\end{array}$ & 53 \\
\hline 27 & PV patch enlargement & In situ pericardium repair & $\begin{array}{l}\text { Alive; echocardiography: } \\
\text { PRV, } 40 \mathrm{~mm} \mathrm{Hg}\end{array}$ & 37 \\
\hline 3 & In situ pericardium repair & & $\begin{array}{l}\text { Alive; catheterization: } \\
\text { MPAP, } 20 \mathrm{~mm} \mathrm{Hg}\end{array}$ & 20 \\
\hline 1.2 & In situ pericardium repair & & $\begin{array}{l}\text { Alive; echocardiography: } \\
\text { PRV, } 30 \mathrm{~mm} \mathrm{Hg}\end{array}$ & 9 \\
\hline 3 & No reoperation & & Death before reoperation & - \\
\hline 3 & PV patch enlargement; 1 left PV stent & & $\begin{array}{l}\text { Alive; echocardiography: } \\
\text { PRV, } 40 \mathrm{~mm} \mathrm{Hg} \text {; } \\
1 \text { stented left PV occluded }\end{array}$ & 59 \\
\hline 15 & $\begin{array}{l}\text { Anastomotic patch enlargement; } \\
\text { PV endarterectomy }\end{array}$ & In situ pericardium repair & $\begin{array}{l}\text { Alive; catheterization: } \\
\text { MPAP, } 25 \mathrm{~mm} \mathrm{Hg}\end{array}$ & 48 \\
\hline 2 & $\begin{array}{l}\text { In situ pericardium repair; } \\
\text { incision left PV }\end{array}$ & & $\begin{array}{l}\text { Operative death; } \\
\text { pneumonia, } 1 \text { left P VO }\end{array}$ & - \\
\hline 3 & $\begin{array}{l}\text { In situ pericardium repair; } \\
\text { incision left PV }\end{array}$ & & $\begin{array}{l}\text { Alive; catheterization: } \\
\text { MPAP, } 30 \mathrm{~mm} \mathrm{Hg} \\
1 \text { left PV stenosis }\end{array}$ & 16 \\
\hline 13 & PV patch enlargement & & Operative death & - \\
\hline 2 & $\begin{array}{l}\text { Anastomotic patch enlargement; } \\
\text { PV endarterectomy }\end{array}$ & $\begin{array}{l}\text { In situ pericardium repair; } \\
\text { incision left PV }\end{array}$ & Operative death; 2 left PVO & - \\
\hline
\end{tabular}

pulmonary veins seem to be more frequently involved (20 right-sided pulmonary veins for 13 left-sided pulmonary veins), and both the right-sided veins were obstructed in 9 of 13 cases. The lesions were bilateral in 7 patients and unilateral in 6 patients.

Classic surgical techniques. As shown on Tables I and II, different surgical techniques were used according to the lesions, the 4 operators involved, and the period of time that elapsed in this retrospective study. Endarterectomy of the intimal hyperplasia was used 5 times either at the site of the anastomosis or on the pulmonary vein ostia; this technique was abandoned. Patch enlargement of the anastomosis and/or the pulmonary ostia was applied 8 times, with twice the native atrial tissue, as described by Pacifico and colleagues, ${ }^{3}$ or elsewhere with polytetrafluoroethlylene* and tanned or native pericardial patches. Interventional cardiology was

*W. L. Gore \& Associates, Inc, Newark, Del.
Table II. Procedures in patients with more than 1 PVO

\begin{tabular}{lccc}
\hline Procedures & $n$ & Success & Failure \\
\hline $\begin{array}{l}\text { PV patch enlargement and/or } \\
\text { endarterectomy }\end{array}$ & 6 & 2 & 4 \\
$\begin{array}{l}\text { In situ pericardium repair } \\
1 \text { PV stenting }\end{array}$ & 7 & 5 & $2^{*}$ \\
\hline
\end{tabular}

$P V$, Pulmonary vein

$* P=.17$.

used twice, to balloon dilate an isolated anastomotic stenosis in 1 patient and to stent intraoperatively a left-sided pulmonary vein in another patient.

Sutureless in situ pericardium repair. After repeated failure with the use of these classic methods (Table II), a new procedure $^{2}$ was used in 7 patients with various PVOs after 3 infracardiac, 2 supracardiac, and 2 mixed TAPVC repairs. 


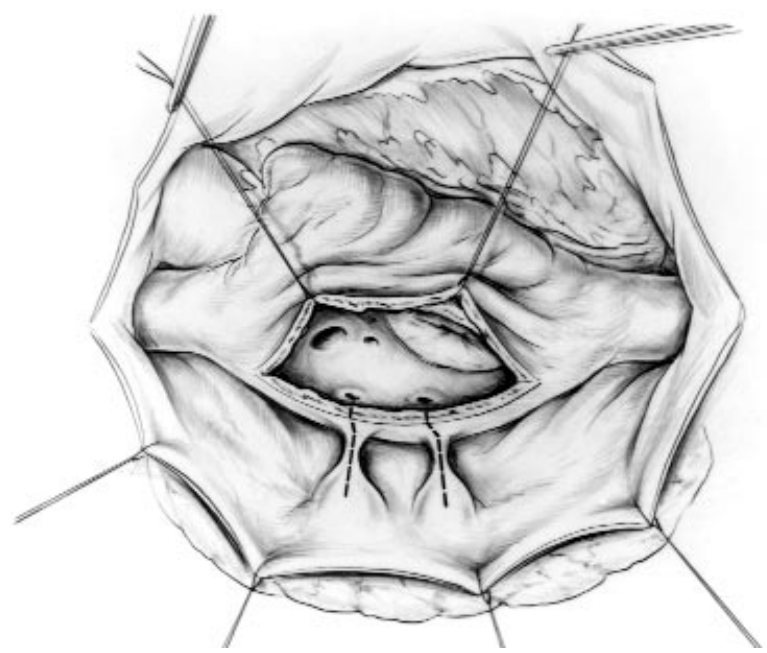

Fig 1. The right-sided pulmonary veins are dissected up to the pericardium. Care is taken not to dissect behind the venae cavae. The left atrium is approached through the interatrial septum or directly above the right-sided pulmonary vein. The right-sided pulmonary veins are incised from their left atrial ostium, all the way up to the pericardial reflection.

This technique ${ }^{2}$ was successfully attempted in April 1995, in a 3-year-old boy, in whom a PVO obstruction had developed on 3 pulmonary veins, after a neonatal repair of an infradiaphragmatic TAPVC. A first reoperation, with pulmonary vein endarterectomy, that was performed 3 months earlier had failed to correct the condition, and this procedure was attempted at a second reoperation (patient 10).

This technique is greatly helped by the presence of pericardial adhesions and was used when the PVO involved the right-sided pulmonary vein. After redo sternotomy, the right atrial wall is dissected free to the right pulmonary veins, which are dissected up the pericardium (Fig 1). Care is taken not to dissect behind the venae cavae and to preserve a large vascularized flap of the right pericardial wall. The operation is undertaken under circulatory arrest with a single cannula in the right atrium. The left atrium is approached either through the interatrial septum or directly at the level of the right-sided pulmonary veins. The left atrium is explored. When there is an associated anastomotic stenosis, it realizes an aspect of acquired cor triatrium with a stenotic orifice that can be found reduced to $1 \mathrm{~mm}$. In the absence of associated anastomotic stenosis, the pulmonary vein ostia are found directly. According to the gravity, 1 to several pulmonary veins are involved. It has been difficult in some instances to recognize a pulmonary vein ostium that barely admits the tip of an instrument. The right-sided pulmonary veins are incised from their left-sided atrial ostium, all the way up to the pericardial reflection, to reach normal noninflammatory intimal tissue (Fig 1). The right-sided pulmonary vein pathologic tissue was resected along with a part of the atrial wall in 4 patients (Fig 2) and left in place in 3 other patients (Fig 3), where the right-sided

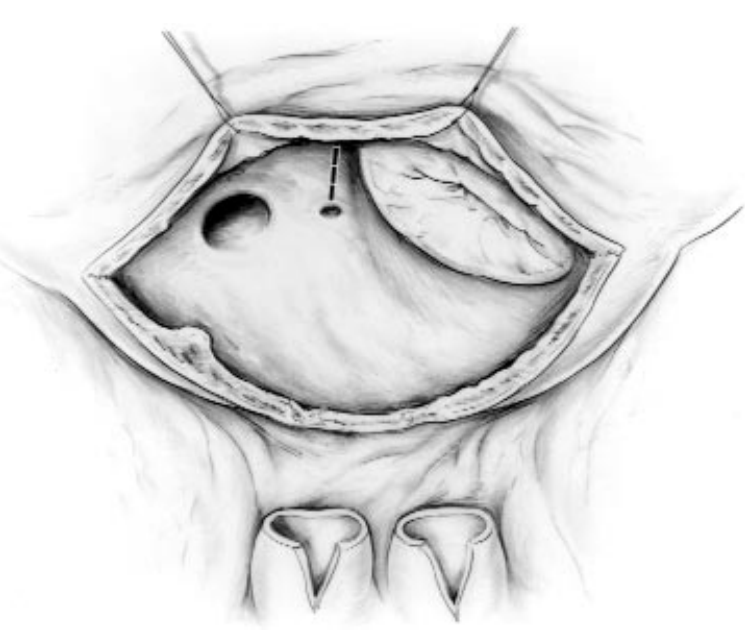

Fig 2. The right-sided pulmonary vein pathologic tissue is totally resected along with a part of left atrial wall. A leftsided pulmonary vein is incised superiorly toward the posterior pericardial cavity maintained sealed by adhesions.

pulmonary veins were only unroofed. Three times the leftsided pulmonary vein was also involved; the left-sided ostium was incised longitudinally, and the incision prolonged outside of the heart into the posterior pericardial cavity, maintained closed by the pericardial adhesions (Figs 2 and 3). An additional patch was used twice to reconstruct the interatrial septum. ${ }^{2}$ Then a vascularized flap of native pericardium (Fig 4) is anastomosed to the right atrial wall, to create a pouch of in situ pericardium that passively drains the right-sided pulmonary vein into the wide-open left atrium. The right phrenic nerve is usually more posterior and not in danger during this procedure. When the pulmonary vein is resected along with the atrial wall, it is useful to secure the resected free left dorsal atrial wall to the posterior pericardium by several sutures to prevent a potential posterior hemorrhage.

\section{Results}

Deaths. The overall mortality rate was $31 \%$ (5 of 16 patients; 95\% confidence limit, 13\%-49\%). Patient 1, who underwent bilateral PVO that involved 2 veins, died before reoperation. There have been 4 deaths after reoperations. Two deaths were after classic anastomotic and pulmonary vein patch enlargement (patient 2 had a bilateral PVO involving 4 veins; patient 9 had an associated single ventricle with heterotaxy and died after concomitant bidirectional Glenn anastomosis, from a pulmonary hypertension crisis). Two patients died after sutureless in situ pericardial repair. Patient 11, who underwent a 4-vein PVO, died 3 weeks after a second reoperation. At autopsy there was a recurrent stenosis of the left-sided pulmonary vein, and the rightsided pulmonary veins were patent. Patient 13 , who 


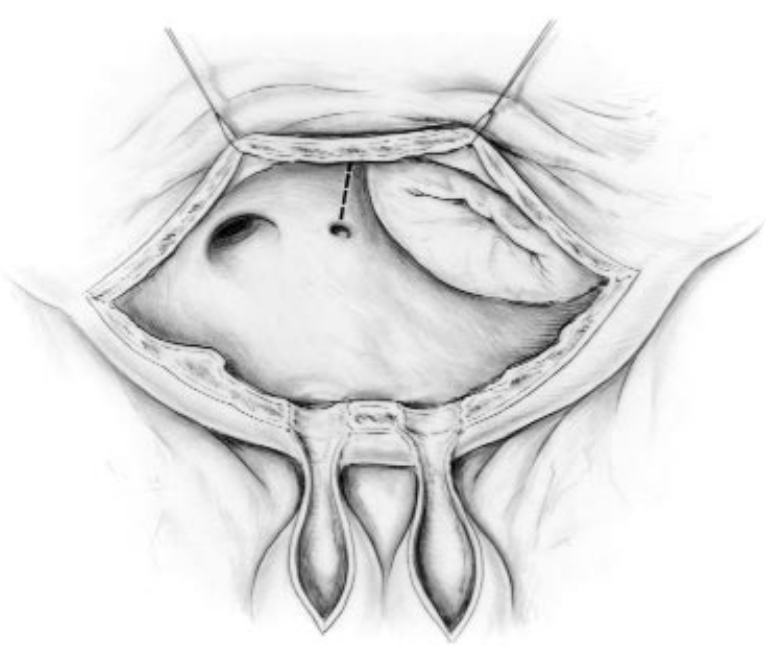

Fig 3. The right-sided pulmonary veins are unroofed, and the pathologic tissue is left in place.

underwent a 3-vein PVO, had an associated staphylococcus pneumopathy and died 5 weeks after reoperation; the right-sided pulmonary veins were patent, but there was a recurrent left-sided pulmonary vein stenosis at echocardiography.

Mortality risk factors. Excluding the patient with single ventricle, the only mortality risk factor that could be recognized is the unilateral or bilateral aspect of the PVO. Of the 13 patients with obstruction at the site of the pulmonary vein (Table I), there were 6 patients with unilateral lesions and 7 patients with bilateral lesions. The mortality rate in unilateral PVO was $0 \%$ (0 of 6 patients) compared with $57 \%$ (4 of 7 patients $)$ in bilateral lesions $(P=.045)$. There was a $100 \%$ mortality rate in the 2 patients with 4 pulmonary veins that were obstructed. Comparing the different procedures used in patients with more than 1 PVO (Table II), the failure with the classic techniques was $67 \%$ (4 of 6 patients) compared to $28.5 \%$ ( 2 of 7 patients) with the in situ pericardium technique, although this difference is not statistically significant $(P=.17)$, because of the small number of patients.

The 2 deaths observed after in situ pericardial repair were partially related to failure in relief of the leftsided PVO. There was no death at in situ pericardial repair when the obstruction involved only the rightsided pulmonary vein ( 0 of 3 patient).

Follow-up time. The mean follow-up time for all the groups is $47 \pm 35$ months, ranging from 9 months to 12 years. All patients are in New York Heart Association class I and had normalized right ventricular systolic pressure at the last echocardiographic examination.

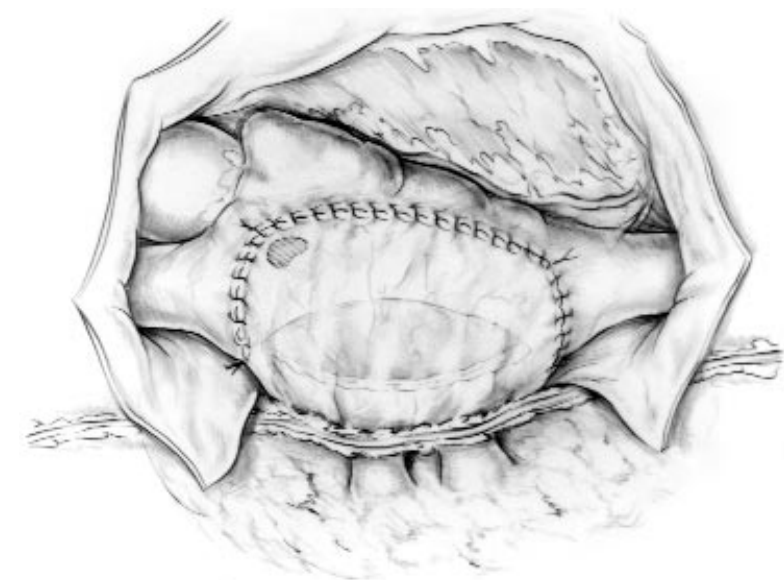

Fig 4. A vascularized flap of native pericardium is anastomosed to the right atrial wall to create a pouch of in situ pericardium that passively drains the right-sided pulmonary vein into the wide opened left atrium. The right-sided phrenic nerve is usually more posterior and not in danger during this procedure.

One left-sided pulmonary vein, previously stented (patient 4), was absent at echocardiogram; however, the right ventricular systolic pressure was less than $50 \%$ systemic. The mean follow-up time for the 5 survivors who underwent the in situ pericardium technique is 26 \pm 16 months, ranging from 9 months to 4 years. Three patients had an angiographic control 1 year after the sutureless repair, with excellent results on the rightsided pulmonary vein and a mild residual stenosis on 1 left-sided pulmonary vein in patient 15 , with a mean pulmonary artery pressure at 20,25 , and $30 \mathrm{~mm} \mathrm{Hg}$, respectively.

\section{Comments}

The occurrence of a progressive PVO varies from $0 \%$ to $18 \%$ in the literature. ${ }^{4}$ As underlined by Van de Wall and colleagues, ${ }^{4}$ an obstruction strictly limited at the site of the anastomosis carries a better prognosis than the obstruction located on the individual pulmonary veins, where the mortality rate approaches $100 \%$ at reoperation. Actually, the most frequent aspect met in our patients was an association of an anastomosis stricture with a various degree of PVO that involved the individual pulmonary veins. It seems that the intimal hyperplasia process that probably starts at the anastomotic suture site extends more or less toward the pulmonary vein ostia located very close by. According to the anatomic type of TAPVC involved, several authors have reported a more frequent risk in the coronary sinus group ${ }^{5,6}$; in our series, the PVO risk seemed more 
important in the mixed types, although not significant. Small pulmonary vein confluence has been recognized as a risk factor for PVO by Bando and colleagues. ${ }^{6}$ In fact, when the common pulmonary vein is poorly developed, the opening incision runs close to the pulmonary vein ostia, and an obstruction of the pulmonary vein is more likely to occur. A hypoplastic pulmonary vein confluence can be met in all types but more rarely in the supracardiac type in which the transversal common trunk is usually well developed. Curiously, PVO was as well observed in supracardiac types, in which the initial anastomosis was wide and well away from the pulmonary vein ostia; therefore in several instances, the occurrence of a PVO seems unpredictable.

In 1 patient with a mixed type (patient 15), a moderate gradient appeared early at 3 weeks after the repair. This patient was placed on oral steroid therapy in a dose of $2 \mathrm{mg} / \mathrm{kg}$ to prevent a more severe stenosis; 6 weeks later the steroids were discontinued in the absence of gradient at echocardiograhy. Two weeks after discontinuation of steroids, he experienced the development of a severe PVO on 3 veins that required reoperation. Sands and colleagues ${ }^{7}$ reported on 2 patients in whom PVO was prevented after 6 months of steroid therapy.

The role of the suture material has been questioned by Hawkins and colleagues, ${ }^{8}$ who advocated the use of absorbable polydioxanone suture to prevent PVO. The satisfactory growth of suture line with polypropylene, which we have observed in other neonatal operations, did not support this difference.

Apart from the progressive PVO is the obstruction observed immediately after the operation. Undue traumatism of the pulmonary vein or undue incision extended toward the pulmonary vein ostium can be the cause; we favor a "no touch" technique provided the propensity to stenosis of the pulmonary vein tissue. Elsewhere, the causes are more related to an adverse anatomy with a native hypoplasia of the pulmonary vein confluence ${ }^{6}$ or a common trunk located far away from the left-sided atrial and resulting in an important tension on 1 or several pulmonary veins.

The PVO occurring in patients with single-functioning ventricle with visceral heterotaxy raises the problem of the source of pulmonary blood flow ${ }^{9}$; potential pulmonary hypertension crises can be fatal in the presence of a bicavopulmonary anastomosis, as was the case in our patient.

Poor results after pulmonary vein stenting has already been reported by Coles and colleagues. ${ }^{10}$ Pulmonary vein stenting was attempted in patient 4; at late follow up, the left-sided pulmonary vein stented was found occluded, although well tolerated.
The relief of PVO with classic procedures is associated in the literature ${ }^{4}$ and in our own experience with a high risk of failure (67\%; Table II). Subsequently, we developed this sutureless procedure using the in situ pericardium. ${ }^{2}$ This technique was proposed years ago in the Senning procedure ${ }^{11}$ and has been used recently by others with satisfactory results. ${ }^{12}$

This technique offers excellent results on the rightsided PVO. It seems preferable, in our personal experience, to perform a large resection of the right-sided pulmonary veins (as shown in Fig 2) than to perform a limited unroofing (Fig 3) that leaves in place a pathologic tissue that could potentially create a restenosis. The left-sided PVO was treated with the same principle in incising the left pulmonary vein from the intra-atrial obstructed ostium toward the extracardiac segment of the pulmonary vein, outside the heart. Thereafter, the enlarged left pulmonary vein drains passively through a posterior pericardial pouch maintained sealed by the postoperative adhesions. The results obtained on the left side require further confirmation; actually, a generous resection of the stenosed pulmonary vein (left- and right-sided) extended up to the normal pulmonary vein tissue is probably more efficient than a simple unroofing. Nevertheless, it seems that a residual single pulmonary vein stenosis can be well tolerated, as in the case in 2 patients in this series (patients 4 and 15). Looking at the degree of pulmonary hypertension generated by PVO, it seems that, if a single PVO can be seen with moderate elevation of pulmonary pressure, a PVO involving 2 veins is almost constantly associated with isosystemic or suprasystemic pulmonary pressure, the lesion being unilateral ( 2 veins on 1 side) or bilateral (1 vein on either side).

This technique, used in acquired pulmonary vein stenosis, could be applied to congenital pulmonary vein stenoses, excluding the patients with diffuse veno occlusive disease into the hilum. ${ }^{13}$ The absence of pericardial adhesions and the risk of posterior hemorrhage can be controlled by suturing the posterior wall of the left atrium to the dorsal part of the pericardium.

In conclusion, progressive PVO remains at risk after TAPVC repair. PVO involving the individual pulmonary vein must be distinguished from the isolated anastomotic stricture. PVO carries a high risk when bilateral. Relief of PVO with a sutureless procedure using in situ pericardium was successfully applied in 5 patients, with excellent results on the right-sided pulmonary vein. Residual moderate stenosis on a single left-sided pulmonary vein was well tolerated. This technique has become the procedure of choice since 1995 in our department and was used in each of the last 7 PVOs observed. 


\section{REFERENCES}

1. Serraf A, Lacour-Gayet F, Bruniaux J, et al. Obstructed total anomalous pulmonary venous return: toward neutralization of a major risk factor. J Thorac Cardiovasc Surg 1991;101:601-6.

2. Lacour-Gayet F, Rey C, Planché C. Pulmonary vein stenosis: description of a sutureless surgical technique using the in situ pericardium. Arch Mal Coeur Vaiss 1996;89:633-6.

3. Pacifico AD, Mandke NV, McGrath LB, Colvin EV, Bini RM, Bargeron LM. Repair of congenital pulmonary venous stenosis with living autologous atrial tissue. J Thorac Cardiovasc Surg 1985;89:604-9.

4. Van de Wal HJCM, Hamilton DI, Godman MJ, Harinck E, Lacquet LK, Van Oort A. Pulmonary venous obstruction following correction for total anomalous pulmonary venous drainage: a challenge. Eur J Cardiothorac Surg 1992;6:545-9.

5. Jonas RA, Smolinsky A, Mayer JE, Castaneda AR. Obstructed pulmonary venous drainage with total anomalous pulmonary venous connection to the coronary sinus. Am J Cardiol 1987;59: 431-5.

6. Bando K, Turrentine MW, Ensing GJ, et al. Surgical management of total anomalous pulmonary venous connection: thirty-year trends. Circulation 1996;94(suppl):12-6.

7. Sands A, Craig B, Casey F. A possible role for steroid therapy in preventing postoperative stenosis in TAPVC. Cardiol Young 1998;8:240-2.

8. Hawkins JA, Minich LL, Tani LY, Ruttenberg HD, Sturtevant JE, McGough EC. Absorbable polydioxanone suture and results in total anomalous pulmonary venous connection. Ann Thorac Surg 1995;60:55-9.

9. Heinemann MK, Hanley FL, Van Praagh S, et al. Total anomalous pulmonary venous drainage in newborns with visceral heterotaxy. Ann Thorac Surg 1994;57:88-91.

10. Coles JG, Yemets I, Najm HK, et al. Experience with repair of congenital heart defects using adjunctive endovascular devices. J Thorac Cardiovasc Surg 1995;110:1513-20.

11. Senning A. Correction of the transposition of the great arteries. Ann Surg 1975;182:287-92.

12. Najm HK, Caldarone CA, Smallhorn J, Coles JG. A sutureless technique for the relief of pulmonary vein stenosis with the use of in situ pericardium. J Thorac Cardiovasc Surg 1998;115:46870.

13. Mendeloff EN, Spray TL, Huddleston CB, Bridges ND, Canter $\mathrm{CB}$, Mallory GB Jr. Lung transplantation for congenital pulmonary vein stenosis. Ann Thorac Surg 1995;60:903-6.

\section{Discussion}

Dr Thomas L. Spray (Philadelphia, Pa). Your series of 178 patients who underwent total anomalous pulmonary venous return and correction over the past 15 years is 1 of the largest ever presented. The presence of anastomotic and PVO in 16 of the patients (approximately 9\%) in this series emphasizes the potential problems with repair of this cardiac lesion.

You commented that the technique of the repair assiduously avoids incision into the pulmonary veins of the common pulmonary venous confluence at the time of anastomosis into the back of the atrium during the repair of this anomaly. You suggest that such an incision into the pulmonary veins would be more likely, rather than less likely, to cause PVO. However, in my own experience with this lesion and with routine incision into all 4 pulmonary veins at the time of the primary repair, recurrent venous obstruction has been exceedingly unusual. In fact, specifically only 2 patients in my experience have ever experienced the development of recurrent venous obstruction, and in both of these cases the veins were not addressed and were not incised at the time of the original operation.

In 1 of these patients, all 4 pulmonary veins entered the right atrium as separate orifices and were not incised at the initial operation; in the second patient, the veins entered as a cardiac form of anomalous venous return, and the coronary sinus was cut back but not extended into the venous orifices themselves. Thus it may, in fact, be possible that the incision into the pulmonary veins for a short distance and creation of a larger venous confluence may prevent the occurrence of this complication, which appears to occur very early after the initial repair in the series presented today. The median time of development of recurrence in this series, as was noted, is only 4 months.

Would you comment on whether the approach to the primary operation has now changed as the result of the recurrent stenosis you have seen in you own series? Have you modified your technique at all for the initial repair?

An additional comment involves the continuing problem of left-sided pulmonary vein obstruction. Although you were able to successfully relieve right-sided PVO by use of this sutureless pericardial technique, the left-sided pulmonary veins continue to be a recurrent problem. You note that the mortality rate in unilateral PVO was zero as compared with the $57 \%$ in bilateral lesions; there appears to be a $100 \%$ mortality rate in the 2 patients who had all 4 pulmonary veins involved.

You note that the 2 deaths observed after in situ repair were partially related to the failure of relief of the left-sided PVO. I therefore wonder whether pulmonary arterial pressures were measured in these patients after the operation (the ones who had, at least, suboptimal relief of left-sided venous obstruction). It is difficult to understand why left-sided PVO would be a high mortality risk if the right-sided pulmonary veins can provide unobstructed flow into the atrium.

It would be of value to know what happened to the pulmonary artery pressure in all of these patients immediately after the repair: the preoperative pulmonary artery pressure in patients with unilateral versus bilateral obstructions and the postoperative pressure change in patients who underwent successful repair of the right-sided veins but had some residual left-sided obstruction.

Perhaps what we are really looking at as an end-point in these patients is the achievement of a low pressure pulmonary artery bed; and in fact, the outcome variable that we may need to look at is in the pulmonary artery pressure rather than relief of venous obstruction.

Were perfusion scans performed in any of these patients to look at differential pulmonary blood flow and to detect minor differences in recurrent PVO, especially on the left side because pulmonary pressure alone may not unmask relative PVO on 1 side or the other? 
You comment that the results of the sutureless pericardial technique were not always satisfactory in the left-sided pulmonary veins. Unlike the authors, we have elected on the left side to incise the base of the left-sided atrial appendage, carry that incision onto the pulmonary veins, and use the flap of left-sided atrial appendage to cover the veins in the pericardial space and not to rely on adhesions from previous operations to contain the venous drainage.

You commented in the discussion that potential changes in the technique for left-sided venous obstruction might be advisable. I wonder if you could comment on any potential differences you might use now in your relief of left-sided venous obstruction because it seems to be such a problem?

Finally, you suggest that this sutureless pericardial technique might have a role to play in the relief of true congenital pulmonary vein stenosis as an alternative to lung transplantation. It is important to note that, in our own series of lung transplantation for congenital pulmonary vein stenosis, the diagnosis of total anomalous pulmonary venous return that had previously been repaired was extremely unusual. That is not the same lesion as congenital PVO.

Only 1 patient in our series of lung transplantations in St Louis (and of an additional 13 patients in Philadelphia, only 1 additional patient) had any evidence of the previous repair of total anomalous venous return before being considered for lung transplantation. The remaining patients all had varying degrees of long segment and ostial obstruction of the pulmonary veins with normal pulmonary venous return.

Specifically, these patients do not have any dilation of the proximal pulmonary veins, so obstruction typically occurs with severe pulmonary hypertension, which does not respond to surgical intervention. Therefore these patients may represent a very different pathophysiologic condition than recurrent PVO in patients who have had repair previously and have obstruction at the pulmonary venous confluence and at the individual pulmonary vein entrances. Attempts at surgical intervention or stenting have been of little value in this subgroup of patients who have progressive pulmonary hypertension despite what appears to be quite adequate initial relief of venous obstruction.

It is clear that there is a heterogenous group of patients with PVO, including those with heterotaxy syndromes, patients who have had previous repairs of total anomalous pulmonary venous return, and patients with congenital PVO. Your interesting use of a new surgical technique to relieve venous obstruction is a major new addition to the surgical armamentarium for this condition; however, the utility of surgical techniques in the varying subsets of patients with this condition remains to be determined.

Dr Lacour-Gayet. The first question concerns the initial operation and potential effect of incising the pulmonary vein.

It is our experience that pulmonary vein manipulation of any kind can be complicated by stenosis, and there are many publications, including your experience in single ventricle, to believe that the pulmonary venous tissue is very likely to be easily stenosed. Therefore this is why, for many years now, we have tried not to open the pulmonary vein ostium during the anastomosis and not to control the pulmonary veins during the operation.

The second question concerns the pulmonary artery pressure in the 2 patients who have exhibited some residual stenosis on the left-sided pulmonary vein. All survivors who have had echocardiographic and angiocardiographic examinations had normal pulmonary artery pressure. We did not perform catheterization in these patients who had residual pulmonary vein stenosis because they were in real poor clinical condition after several reoperations. On the other end, I must say that there is a suspicion that many patients operated from TAPVD and normally surviving might have 1 pulmonary vein blocked that is totally silent.

Your next question concerned the indication of lung transplantation that was mentioned in the article. What I wanted to underline is that this operation, which has been applied to acquired pulmonary vein stenosis, could be also applied to native congenital pulmonary vein stenosis.

I certainly do agree with you that patients who have atretic pulmonary vein lesions inside the lung are, of course, incompatible with the technique that I have proposed.

\section{Commentary}

Lacour-Gayet and his associates from the MarieLannelongue Hospital in Paris present in this issue their experience with 16 patients in whom single or multiple unilateral or bilateral pulmonary vein stenosis (PVS) developed after repair of total anomalous pulmonary venous connection (TAPVC). ${ }^{1}$ Although the authors initially used different techniques with varying degrees of success, the most appealing and useful technique proved to be the "in situ pericardial pouch plasty," which is very well described and illustrated in their text.

The concept of using an in situ pericardial pouch plasty was first described (to the best of my knowledge) by Åke Senning in 1975 as an adjunct to his original operation for transposition of the great arteries. ${ }^{2}$ On that occasion I commented on some difficulties we had encountered with acquired right pulmonary vein obstruction in very young infants after the original Senning atrial switch operation. Since that initial experience, $\mathrm{we}^{3}$ routinely added a very similar in situ pericardial pouch plasty to all of our Senning operations in infants.

The adaptation of this technical maneuver by LacourGayet and his associates for the relief of the hitherto challenging problem of acquired PVS after repair of TAPVC is ingenious and represents an important addition to our pediatric cardiac surgical armamentarium. Although the authors recommend this technique for relief of acquired PVS, it should be equally applicable 
to the rare cases of congenital PVS. As to the presence of bilateral PVS, the left-sided PVS should also lend itself, particularly in neonates and infants, to an in situ pericardial pouch plasty through a midline sternotomy.

Lacour-Gayet and his associates deserve much credit for this very useful surgical-technical contribution for the relief of pulmonary venous obstructive lesions.

Aldo Castañeda, MD Guatemala City, Guatemala

\section{REFERENCES}

1. Lacour-Gayet F, Zoghby J, Serraf A, Belli E, Piot D, Rey C, et al. Surgical management of progressive pulmonary venous obstruction after repair of total anomalous pulmonary venous connection. J Thorac Cardiovasc Surg 1999;117:679-87.

2. Senning A. Correction of the transposition of the great arteries. Ann Surg 1975;182:287-92.

3. Castañeda A, Jonas RA, Mayer J, Hanley FL. Cardiac surgery of the neonate and infant. Philadelphia: WB Saunders. 1994.

$12 / 6 / 97597$

\section{ON THE M OVE?}

Send us your new address at least six weeks ahead

Don't miss a single issue of the journal! To ensure prompt service when you change your address, please photocopy and complete the form below.

Please send your change of address notification at least six weeks before your move to ensure continued service. We regret we cannot guarantee replacement of issues missed due to late notification.

\section{JOURNAL TITLE:}

Fill in the title of the journal here.

\section{OLD ADDRESS:}

Affix the address label from a recent issue of the journal here.

\section{NEW ADDRESS: \\ Clearly print your new address here.}

Name

Address

City/State/ZIP

\section{COPY AND MAIL THIS FORM TO:}

Periodical Subscription Services

Mosby, Inc.

11830 Westline Industrial Dr.

St. Louis, MO 63146-3318
OR FAX TO:

314-432-1158

N/M Mosby

\section{OR PHONE:}

1-800-453-4351

Outside the U.S., call

314-453-4351 